\section{A CD Exciton Chirality Method for Determination of the Absolute Configuration of threo- $\beta$-Aryl- $\beta$-hydroxy- $\alpha$-amino Acid Derivatives}

\author{
Lee-Chiang Lo,* Chun-Tzu Yang, and \\ Charng-Sheng Tsai
}

Department of Chemistry, National Taiwan University, Taipe 106, Taiwan

Iclo@ccms.ntu.edu.tw

Received August 29, 2001

\begin{abstract}
The absolute configuration of threo- $\beta$-aryl- $\beta$ hydroxy- $\alpha$-amino acids was studied by CD exciton chirality method using 7-diethylaminocoumarin-3-carboxylate as a red-shifted chromophore. Bischromophoric derivatives for a series of threo- $\beta$-aryl- $\beta$-hydroxy- $\alpha$-amino acids ( $3 \mathbf{a}-\mathbf{h}$ ) were prepared and their $\mathrm{CD}$ spectra measured in $\mathrm{CH}_{2} \mathrm{Cl}_{2}$. By combining the data of $\mathrm{CD}$ and NMR coupling constants, we are able to correlate their preferred conformer (B) and the positive $C D$ to the corresponding ( $2 S, 3 R$ )-absolute configuration. These results are consistent with those obtained from serine and threonine derivatives, which represent the simplest form of $\beta$-hydroxy- $\alpha$-amino acids. This CD method could thus become a general method for determining the absolute configuration of threo- $\beta$-aryl- $\beta$-hydroxy- $\alpha$-amino acids.
\end{abstract}

$\beta$-Hydroxy- $\alpha$-amino acids belong to a class of compounds of medicinal importance. They have been found in many natural products possessing a wide range of biological properties. ${ }^{1}$ Besides, they could serve as useful precursors and chiral auxiliaries in organic synthesis. ${ }^{2}$ Therefore, a large number of synthetic efforts, utilizing chemical and enzymatic methods, ${ }^{3,4}$ have focused on this

(1) Solenberg, P. J .; Matsushima, P.; Stack, D. K.; Wilkie, S. C. Thomson, R. C.; Baltz, R. H. Chem. Biol. 1997, 4, 195-202. Saeed, A.; Young, D. W. Tetrahedron 1992, 48, 2507-2514.

(2) Evans, D. A.; Dinsmore, C.J .; Ratz, A. M.; Evrard, D. A.; Barrow J. C. J . Am. Chem. Soc. 1997, 119, 3417-3418. Shibata, K.; Shingu, K.; Vassilev, V. P.; Nishide, K.; Fujita, T.; Node, M.; Kajimoto, T.; Wong, C.-H. Tetrahedron Lett. 1996, 37, 2791-2794. Drueckhammer, D. G.; Barbas, C. F., III; Nozaki, K.; Wong, C.-H. J . Org. Chem. 1988 53, 1607-1611. Coppola, G. M.; Schuster, H. F. Asymmetric Synthe sis: Construction of Chiral Molecules Using Amino Acids; J ohn Wiley \& Sons: Toronto, 1987. Millar, M. J . Acc. Chem. Res. 1986, 19, 4956.

(3) Kuwano, R.; Okuda, S.; I to, Y. J . Org. Chem. 1998, 63, 34993503. Li, G.; Chang, H.-T.; Sharpless, K. B. Angew. Chem., Int. Ed. Engl. 1996, 35, 451-454. Kol b, H. C.; VanNieuwenhze, M. S.; Sharpless, K. B. Chem. Rev. 1994, 94, 2483-2547. Seebach, D.; J uaristi, E.; Miller, D. D.; Schickli, C.; Weber, T. Helv. Chim. Acta 1987, 70, 237261. Evans, D. A.; Weber, A. E. J . Am. Chem. Soc. 1986, 108, 67576761.

(4) Kimura, T.; Vassilev, V. P.; Shen, G. J .; Wong, C. H. J . Am. Chem. Soc. 1997, 119, 11734-11742. Vassilev, V. P.; Uchiyama, T.; Kajimoto, T.; Wong, C.-H. Tetrahedron Lett. 1995, 36, 4081-4084. Herbert, R. B.; Wilkinson, B.; Ellames, G. J .; Kunec, E. K. J . Chem. Soc., Chem. Commun. 1993, 205-206. Lotz, B. T.; Gasparski, C. M.; Peterson, K.; Miller, M. J .J . Chem. Soc., Chem. Commun. 1990, 11071109. type of target. $\beta$-Aryl- $\beta$-hydroxy- $\alpha$-amino acids, a subclass of $\beta$-hydroxy- $\alpha$-amino acids carrying an aromatic substituent at the $\beta$-position, are of special interest as they are usually a key constituent of peptide antibiotics, such as chloramphenicol and vancomycin. ${ }^{5}$ Currently, establishment of the absolute configuration of these compounds relies mostly on comparison of their optical rotations with those of authentic samples, an approach which is only applicable to the known compounds. Another indirect approach would derive the results from the stereospecificity of enzymes used for the synthesis. Therefore, it is necessary to develop a spectroscopic method for the determination of the absolute configuration of this class of compounds. In our continuing efforts in studying the stereochemical properties of $\beta$-hydroxy$\alpha$-amino acids, we have developed a convenient CD exciton chirality method using a red-shifted chromophore on model compounds 1 and $\mathbf{2}$ (Figure 1 ). ${ }^{6}$ In this report, we further extend this CD method to the series of threo$\beta$-aryl- $\beta$-hydroxy- $\alpha$-amino acids (3).

The CD exciton chirality method is a nonempirical means and has been widely used for determining the absolute configuration of many natural products. ${ }^{7}$ The electric transition moments of two chromophores interact through space to give an exciton coupled CD spectrum. The sign and intensity of the couplets depend on the handedness of the two chromophores and the distance between them. 7-Diethylaminocoumarin-3-carboxylate (4) is a red-shifted chromophore $\left(\lambda_{\max } 420 \mathrm{~nm}\right.$ in $\left.\mathrm{CH}_{2} \mathrm{Cl}_{2}\right)$ with high $\epsilon$ value (an average $\epsilon$ value of 80000 was used for the bischromophoric derivatives). ${ }^{6,8}$ It gives extremely strong $C D$ couplets on rigid systems such as ( $1 R, 2 R)-1,2-$ diaminocyclohexane $(A=-203)$ and $(1 R, 2 R)$-1,2-cyclohexanediol $(A=-161) .{ }^{8}$ These results suggest that the direction of the electric transition moment corresponding to $420 \mathrm{~nm}$ is al ong the long axis of the chromophore and is parallel to the $\mathrm{C}-\mathrm{N}$ and $\mathrm{C}-\mathrm{O}$ bonds on the parent molecules, as indicated by the arrow in Figure 1 . This highly sensitive property sets the basis for its applications in microscale structural determination. Previous results on simple $\beta$-hydroxy- $\alpha$-amino acids (1 and $\mathbf{2}$ ) showed that the polar carboxylate moiety of compounds $\mathbf{1}$ and $\mathbf{2}$ played an important role in determining the predominant conformer and therefore made them behave differently from other acyclic vic-amino alcohols. ${ }^{6}$ To study the substituent effects of the aromatic ring at the $\beta$-position on the resulting predominant conformer and $\mathrm{CD}$, and to correlate the results to their absolute config-

(5) Rao, A. V. R.; Gurjar, M. K.; Reddy, K. L.; Rao, A. S. Chem. Rev. 1995, 95, 2135-2167. Fles, D.; Balenovic, B. J . Am. Chem. Soc. 1956, 78, 3072-3074.

(6) Lo, L.-C.; Chen, J .-Y.; Yang, C.-T.; Gu, D.-S. Chirality 2001, 13, 266-271.

(7) Berova, N.; Nakanishi, K. In Circular Dichroism-Principles and Applications; Berova, N.; Nakanishi, K.; Woody, R. W., Eds.; WileyVCH: New York, 2000; pp 337-382. Harada, N.; Nakanishi, K. Circular Dichroic Spectroscopy-Exciton Coupling in Organic Stereochemistry; University Science Books: Mill Valley, CA, 1983.

(8) Lo, L.-C.; Liao, Y.-C.; Kuo, C.-H.; Chen, C.-T. Org. Lett. 2000, 2, $683-685$. 

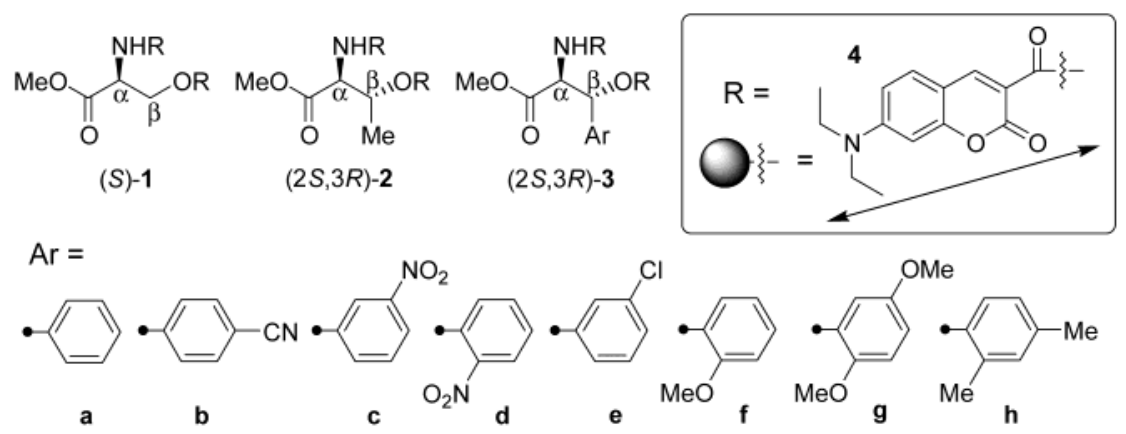

Figure 1. Structures of the bischromophoric derivatives 1-3 and the chromophore 4. The major electric transition moment of chromophore $\mathbf{4}$ is indicated by the arrow.

\section{Scheme 1. Preparation of the Optically Active threo- $\beta$-Aryl- $\beta$-hydroxy- $\alpha$-amino Acid Derivatives 3a-h for} NMR, UVNis, and CD Measurements
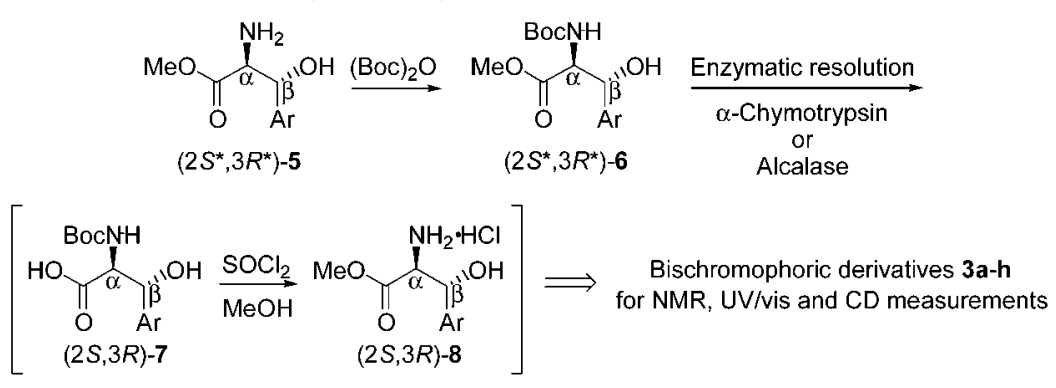

uration, we prepared a series of optically active threo- $\beta$ aryl- $\beta$-hydroxy- $\alpha$-amino acid derivatives (3a-h) and measured their CD (Scheme 1).

Derivatives $\mathbf{3} \mathbf{a}-\mathbf{h}$ cover a wide variety of aromatic substituents (Figure 1), including a simple phenyl ring (3a), electron-withdrawing groups (4-cyano, 3b; 3-nitro, 3c; 2-nitro, 3d; 3-chloro, 3e), and electron-releasing groups (2-methoxy, 3f; 2,5-dimethoxy, 3g; 2,4-dimethyl, $\mathbf{3 h})$. Among these, derivatives $\mathbf{3 d}, \mathbf{3 f}, \mathbf{3 g}$, and $\mathbf{3 h}$ are expected to be more sterically hindered, as they all have a substituent at ortho-position. Scheme 1 depicts the preparation of optically active bischromophoric derivatives $\mathbf{3 a}-\mathbf{h}$ for the CD study. Methyl esters of racemic threo- $\beta$-aryl- $\beta$-hydroxy- $\alpha$-amino acids $\left(2 S^{*}, 3 \mathrm{R}^{*}\right)-5$, prepared from methyl glycinate and corresponding aromatic al dehydes according to literature procedures, ${ }^{9}$ were used as the starting materials. They were first N-Boc-protected to give $\left(2 S^{*}, 3 R^{*}\right)-6$, followed by enzymatic resolution ${ }^{10}$ using either $\alpha$-chymotrypsin or alcalase to offer optically active acids (2S,3R)-7. The Boc group was chosen as the amino protecting group, because it could concomitantly be removed when the acids 7 were treated with $\mathrm{SOCl}_{2} /$ $\mathrm{MeOH}$, offering the methyl esters (2S,3R)-8. The kinetic resolution of methyl esters $\mathbf{6 a}-\mathbf{g}$ was carried out with $\alpha$-chymotrypsin. In the case of ester $\mathbf{6} \boldsymbol{h}$, a poor substrate of $\alpha$-chymotrypsin, alcalase, which has been shown to display a broader substrate specificity, ${ }^{11}$ was used instead. The reaction conditions were not optimized, and they were stopped at $15-20 \%$ conversions to ensure high optical purity of the acid products. Since this reaction

(9) Belokon, Y. N.; Bulychev, A. G.; Vitt. S. V.; Struchkov, Y. T.; Batsanov, A. S.; Timofeeva, T. V.; Tsyryapkin, V. A.; Ryzhov, M. G.; Lysova, L. A.; Bakhmutov, V. I.; Belikov, V. M. J . Am. Chem. Soc. 1985, 107, 4252-4259. Pines, S. H.; Kozlowski, M. A. J . Org. Chem. 1972, 37, 292-297. Ehrhart, G.; Siedel, W.; Nahm, H. Chem. Ber. 1957, 90, 2088-2094.

(10) Wong, C.-H.; Whitesides, G. M. In Enzymes in Synthetic Organic Chemistry; Baldwin, J . E.; Magnus, P. D., Eds.; Elsevier: Oxford, 1994; pp 41-130. scheme was intended to apply to a microscale reaction, the intermediates $\mathbf{7}$ and $\mathbf{8}$ were not purified. The bischromophoric derivatization of (2S,3R)-8 was achieved by a single coupling reaction using DCC/DMAP method. Bischromophoric derivatives $\mathbf{3} \mathbf{a}-\mathbf{h}$ thus obtained were further HPLC-purified before subjected to UV/vis and CD measurements. Enantiomeric excess values of these bischromophoric derivatives were found to be in the range of $80-96 \%$ by ${ }^{1} \mathrm{H}$ NMR analysis in the presence of $\mathrm{EU}$ $(\mathrm{hfc})_{3}$. Well-resolved signals were obtained for the methyl ester protons. ${ }^{12}$

By taking advantage of the red-shifted property of the chromophore as well as the good solubility of the bischromophoric derivatives in $\mathrm{CH}_{2} \mathrm{Cl}_{2}$, we were able to perform all the following UV/vis and CD measurements in this solvent. Furthermore, the results would better correlate to the ${ }^{1} \mathrm{H} N \mathrm{NMR}$ conformational analyses, which were conducted in $\mathrm{CDCl}_{3}$. We started with compound $\mathbf{3 a}$, which carries only a phenyl group at the $\beta$-position and represents the simplest member in the family. Its $\lambda_{\max }$ is around $422 \mathrm{~nm}$, which is typical for derivatives of the red-shifted chromophore 4. The CD of (2S,3R)-3a exhibits an exciton couplet with a positive first Cotton effect (CE) at $432 \mathrm{~nm}(\Delta \epsilon+60)$ and a negative second $C E$ at $398 \mathrm{~nm}$ $(\Delta \epsilon-32)$, leading to an $A$ value of +92 (Table 1$)$. This positive handedness of the two chromophores could be explained from the conformational analysis. There are three staggered conformers for (2S,3R)-3a (Figure 2). The two chromophores are in gauche positions for conformers $\mathbf{A}$ and $\mathbf{B}$, and in anti positions for conformer $\mathbf{C}$. Since

(11) Hwang, B. K.; Gu, Q.-M.; Sih, C. J . J . Am. Chem. Soc. 1993 115, 7912-7913. Wong, C.-H.; Chen, S.-T.; Hennen, W. J .; Bibbs, J. A.; Wang, Y.-F.; Liu, J . L.-C.; Pantoliano, M. W.; Whitlow, M.; Bryan, P. N. J . Am. Chem. Soc. 1990, 112, 945-953. Bones, J. B.; Beck, J. F In Applications of Biochemical Systems in Organic Chemistry; Part I, J ones, J . B.; Sih, C. J .; Perlman, D., Eds.; Wiley: New York, 1976; pp 107-401.

(12) Chênevert, R.; Létourneau, M.; Thiboutot, S. Can. J . Chem 1990, 68, 960-963. Chênevert, R.; Létourneau, M. Chem. Lett. 1986, $1151-1154$. 
Table 1. CD and NMR Coupling Constants of Bischromophoric Derivatives 1, 2, and 3a-h

\begin{tabular}{|c|c|c|c|}
\hline compound & $\mathrm{CD}\left(\mathrm{CH}_{2} \mathrm{Cl}_{2}\right): \lambda_{\text {ext }}(\Delta \epsilon)$ & A value & $\begin{array}{c}\text { coupling constant } \\
\mathrm{J}_{\mathrm{H} \alpha, \mathrm{H} \beta}(\mathrm{Hz})\end{array}$ \\
\hline$(2 S, 3 R)-2$ & $432(+54), 396(-24)$ & +78 & 2.0 \\
\hline$(2 S, 3 R)-3 \mathbf{a}$ & $432(+60), 398(-32)$ & +92 & 2.3 \\
\hline$(2 S, 3 R)-3 b$ & $431(+51), 397(-30)$ & +81 & 2.2 \\
\hline$(2 S, 3 R)-3 c$ & $435(+61), 403(-34)$ & +95 & 1.7 \\
\hline$(2 S, 3 R)-3 d$ & $431(+84), 400(-45)$ & +129 & 2.2 \\
\hline$(2 S, 3 R)-3 e$ & $432(+50), 399(-29)$ & +79 & 2.2 \\
\hline$(2 S, 3 R)-3 f$ & $431(+79), 397(-45)$ & +124 & 1.9 \\
\hline & $431(+58), 398(-34)$ & +92 & 2.0 \\
\hline$(2 S, 3 R)-3 i$ & $431(+52), 398(-29)$ & +82 & 2.0 \\
\hline
\end{tabular}

a Spectra were taken in $\mathrm{CDCl}_{3}$.

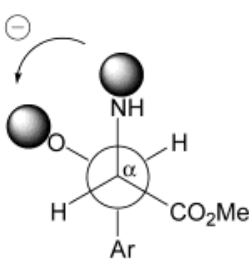

A

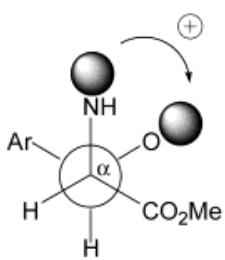

B

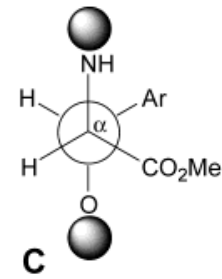

Figure 2. Three staggered conformers $(\mathbf{A}-\mathbf{C})$ of the bischromophoric derivatives $\mathbf{3 a}-\mathbf{h}$.

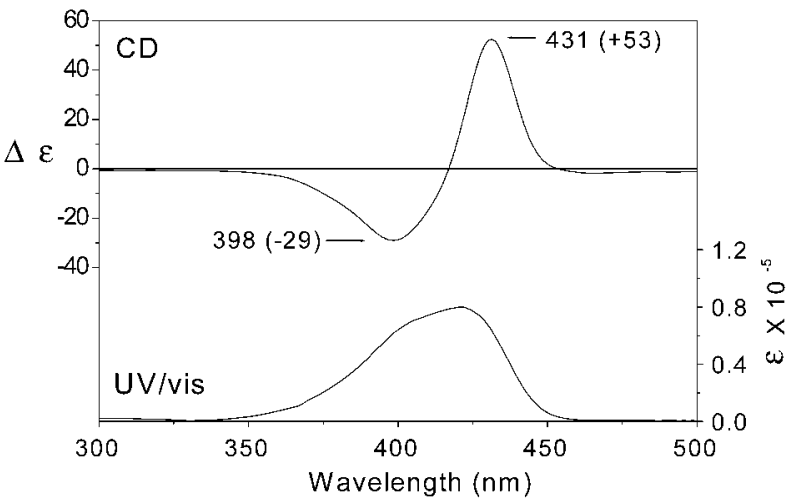

Figure 3. $C D$ and UV/vis spectra of bischromophoric derivative $3 \mathbf{h}$ in $\mathrm{CH}_{2} \mathrm{Cl}_{2}$.

the dihedral angle between the two chromophores in conformer $\mathbf{C}$ is close to $180^{\circ}$, it is not expected to have a significant $C D$. Conformer $\mathbf{A}$ will give a negative $C D$, and conformer B will lead to a positive CD. ${ }^{1} \mathrm{H}$ NMR study provides useful information regarding which conformer will be predominant. The coupling constant between $\mathrm{H}_{\alpha}$ and $\mathrm{H}_{\beta}$ was found to be $2.3 \mathrm{~Hz}$ in $\mathrm{CDCl}_{3}$ (Table 1). It supports that the $\mathrm{H}_{\alpha}$ proton is gauche to the $\mathrm{H}_{\beta}$ proton, therefore, ruling out the possibility of conformer $\mathbf{A}$. Since the observed $C D$ has a strong A value of +92 , we could conclude that (2S,3R)-3a prefers conformer B. This observation of preferred conformer $\mathbf{B}$, leading to positive CD for (2S,3R)-derivatives, is the same as in the case of (2S,3R)-threonine derivative $\mathbf{2}$, which has a methyl group instead of a phenyl ring at the $\beta$-position.

We then studied the substituent effect of the ring by examining the other members of the family $(\mathbf{3 b}-\mathbf{h})$. As a typical example, the CD and UV/vis spectra of compound $\mathbf{3 h}$, the only member derived from alcalasecatalyzed resolution, were shown in Figure 3 . Its $\lambda_{\max }$ is around $423 \mathrm{~nm}$, and its CD exhibits an exciton couplet with a positive first Cotton effect (CE) at $431 \mathrm{~nm}(\Delta \epsilon+53)$ and a negative second CE at $398 \mathrm{~nm}(\Delta \epsilon-29)$, leading to an $A$ value of +82 . Coupling constant between $\mathrm{H}_{\alpha}$ and $\mathrm{H}_{\beta}$ was found to be $2.0 \mathrm{~Hz}$ in $\mathrm{CDCl}_{3}$ (Table 1 ). As a matter of fact, the results for all the (2S,3R)-family members are very consistent. The coupling constant between $\mathrm{H}_{\alpha}$ and $\mathrm{H}_{\beta}$ for all the members falls in the range of $1.7-2.3 \mathrm{~Hz}$, and their CD A values range from +79 to +129 (Table 1). The high $A$ values together with the small coupling constants between $\mathrm{H}_{\alpha}$ and $\mathrm{H}_{\beta}$ hel p rule out the possibility of (2R,3S)-enantiomers adopting conformers A (minor) and $\mathbf{C}$ (major). In this case the A values would be expected to be much smaller, as the contribution from the less populated conformer $\mathbf{A}$ is insignificant. It is therefore a general trend for the threo- $\beta$-aryl- $\beta$-hydroxy$\alpha$-amino acid derivatives to adopt the preferred conformer B. The substituents on the phenyl ring, regardless of their electronic and steric properties, seemed not affect the predominant conformer and the resultant CD. It is noteworthy that the absolute configuration determined from this CD exciton chirality method is in good agreement with the outcome of the enzymatic stereospecificity ${ }^{12}$ used in this report to prepare the (2S,3R)-threo- $\beta$ aryl- $\beta$-hydroxy- $\alpha$-amino acids.

In conclusion, we applied the CD exciton chirality method to the threo- $\beta$-aryl- $\beta$-hydroxy- $\alpha$-amino acids using a red-shifted 7-diethylaminocoumarin-3-carboxylate (4) chromophore. By taking advantage of its red-shifted property, we were able to use $\mathrm{CH}_{2} \mathrm{Cl}_{2}$ as the solvent for $\mathrm{CD}$ and UV/vis measurements in this study. Data from NMR coupling constants as well as the sign and the intensities of CD reveal the preferred conformer $\mathbf{B}$ for this series of compounds. Therefore, the aromatic rings at the $\beta$-position do not make them behave differently from that of threonine derivative, which carries only a methyl group. A positive $C D$ will correspond to (2S,3R)absol ute configuration. This is a convenient and reliable method, and it could generally be applicable to all threo$\beta$-aryl- $\beta$-hydroxy- $\alpha$-amino acids. Our ongoing study is to extend this CD method to the series of erythro- $\beta$-aryl- $\beta$ hydroxy- $\alpha$-amino acids. The results will be reported in due course.

\section{Experimental Section}

General Methods. Melting points are uncorrected. IR spectra were taken with Nicolet Magna-IR 550 Series II. ${ }^{1} \mathrm{H}$ and ${ }^{13} \mathrm{C}$ NMR spectra were recorded at 400 and $100 \mathrm{MHz}$ in $\mathrm{CDCl}_{3}$, respectively. High-resolution mass spectra were recorded on a J EOL-102A mass spectrometer. Analytical TLC (silica gel, 60F54, Merck) and spots were visualized under UV light and/or phosphomolybdic acid-ethanol. Flash column chromatography was performed with silica gel 60 (70-230 mesh, Merck). Spectrophotometric grade of $\mathrm{CH}_{2} \mathrm{Cl}_{2}$ and a J asco J -720 spectropolarimeter were used for obtaining CD spectra. The $\Delta \epsilon$ values were normalized to $100 \%$ optical purity of the corresponding samples.

General Procedure for the Preparation of Boc-Protected Derivatives $\mathbf{6 a}-\mathbf{h}$. To an ice-cooled solution of the corresponding methyl ester $5(1.5 \mathrm{mmol})$ in $25 \mathrm{~mL}$ of $\mathrm{CH}_{2} \mathrm{Cl}_{2}$ was added $(\mathrm{Boc})_{2} \mathrm{O}(1.65 \mathrm{mmol})$. The mixture was gradually allowed to return to room temperature and stirred for $20 \mathrm{~h}$. A solution of $5 \% \mathrm{NaHCO}_{3}(20 \mathrm{~mL})$ was added. The organic layer was separated and dried over anhydrous $\mathrm{Na}_{2} \mathrm{SO}_{4}$. It was filtered and concentrated. The desired product $\mathbf{6}$ was purified with silica gel column chromatography eluted with $\mathrm{CH}_{2} \mathrm{Cl}_{2} / \mathrm{MeOH}(95 / 5 \rightarrow 90 /$ 10).

General Procedure for the Protease-Catalyzed Resolution of $\left(2 S^{*}, 3 R^{*}\right)-6$. $\alpha$-Chymotrypsin was used for compounds $\mathbf{6 a}-\mathbf{g}$, whereas alcalase was used for compound $\mathbf{6 h}$. Individual substrate 6 (1.0 mmol) was suspended in $25 \mathrm{~mL}$ of phosphate buffer $(0.3 \mathrm{M}, \mathrm{pH} 7.0)$ containing $10 \%$ DMF. $\alpha$-Chymotrypsin (25 mg) was added, and the reaction was shaken at $37^{\circ} \mathrm{C}$ for 
$12-24 \mathrm{~h}$. The mixture was then extracted with EtOAc $(25 \mathrm{~mL}$ $\times 6)$ to remove the remaining ester. The aqueous layer was acidified with citric acid and extracted with EtOAc $(30 \mathrm{~mL} \times 3)$. The combined organic layers were washed with brine and dried over anhydrous $\mathrm{Na}_{2} \mathrm{SO}_{4}$. After filtration and concentration, crude acid (2S,3R)-7 was obtained (yield 15-20\%). In the case of compound $\mathbf{6 h}$, alcalase $(2.2 \mathrm{~mL})$ instead of $\alpha$-chymotrypsin was used. The rest part of the procedure was the same. The acid (2S,3R)-7 was used without further purification.

General Procedure for the Methylation and Deprotection of the Boc Group To Give Compounds $8 \mathbf{a}-\mathbf{h}$. To a cooled solution of crude acid $7(0.07 \mathrm{mmol})$ in anhydrous $\mathrm{MeOH}$ $\left(5 \mathrm{~mL}\right.$ ) was added $0.2 \mathrm{~mL}$ of $\mathrm{SOCl}_{2}$. It was stirred at room temperature for $20 \mathrm{~h}$. The mixture was then concentrated to give crude (2S,3R)-8 (yield 60-80\%). It was converted to free amine by adding $10 \% \mathrm{NaHCO}_{3}(5 \mathrm{~mL})$ and extracted with EtOAc (5 $\mathrm{mL}$ ). The EtOAc extract was concentrated and subjected to the bischromophoric derivatization without further purification.

General Procedure for the Preparation of Bischromophoric Derivatives. To an ice-cooled solution of free amine from individual (2S,3R)-8 $(0.05 \mathrm{mmol})$, triethylamine $(0.1 \mathrm{mmol})$, DMAP $(0.05 \mathrm{mmol})$, and 7-diethylaminocoumarin-3-carboxylic acid $(0.11 \mathrm{mmol})$ in $\mathrm{CH}_{2} \mathrm{Cl}_{2}(3 \mathrm{~mL})$ was slowly added a solution of DCC $(0.14 \mathrm{mmol})$ in $\mathrm{CH}_{2} \mathrm{Cl}_{2}(2 \mathrm{~mL})$. The mixture was gradually allowed to return to room temperature and stirred overnight. It was quenched by adding a few drops of $5 \%$ citric acid and stirred for another $30 \mathrm{~min}$. The $\mathrm{CH}_{2} \mathrm{Cl}_{2}$ was removed, and EtOAc was added. The DCU was first filtered off, and the EtOAc filtrate was washed with $10 \% \mathrm{NaHCO}_{3}(\times 3), \mathrm{H}_{2} \mathrm{O}(\times 2)$, and finally with brine. The organic layer was dried over anhydrous $\mathrm{Na}_{2} \mathrm{SO}_{4}$. It was filtered, concentrated, and subjected to silica gel column chromatography for purification. The desired product $\mathbf{3 a}-\mathbf{h}$ was eluted with $\mathrm{CHCl}_{3} / \mathrm{EtOAc}(9 / 1)$. The optical purity of the bischromophoric derivatives $\mathbf{3 a}-\mathbf{h}$ was determined by ${ }^{1} \mathrm{H} N M R$ in the presence of 0.3 equiv of $E u(h f c)_{3}$.

Acknowledgment. This work was supported by the National Science Council (NSC-89-CPC-7-002-012 to L.C.L.).

Supporting Information Available: Data for compounds $\mathbf{3} \mathbf{a}-\mathbf{h}, \mathbf{6} \mathbf{a}-\mathbf{h}$ as well as the ${ }^{1} \mathrm{H}$ and ${ }^{13} \mathrm{C}$ NMR spectra of compounds $\mathbf{3 a}-\mathbf{h}$. This material is available free of charge via the Internet at http://pubs.acs.org.

J O016070L 